\title{
ENSINO JURÍDICO NA BAHIA: A (Des)Valorização da Docência como Carreira Profissional ${ }^{1}$
}

\author{
http://dx.doi.org/10.21527/2176-6622.2019.52.210-223
}

Recebido em: 2/8/2019

Modificações requeridas em: 25/10/2019

Aceito em: 4/11/2019

\section{Quéren Samai Moraes Santana}

Graduanda em Direito pela Universidade Federal da Bahia. Pesquisadora em iniciação científica na área de Ensino Jurídico e Direito do Trabalho. http://lattes.cnpq.br/0690926465587061. queren_samai@hotmail.com

\section{Jose Garcez Ghirardi}

Professor associado e tempo integral da FGV Direito SP (Graduação e Mestrado). Pós-Doutorado no Collège de France (2017), Chaire État Social et mondialisation, com bolsa Fapesp, e na Unicamp (2004). Mestrado e Doutorado em Estudos Linguísticos e Literários em Inglês pela Universidade de São Paulo (1995 e 1998). Advogado formado pela Universidade de São Paulo (1985). Coordenador do Observatório do Ensino do Direito da FGV Direito SP e membro do Conselho Acadêmico do Centro de Ensino e Pesquisa em Inovação da FGV Direito SP. Adjunct Faculty da Gonzaga Law School (WA/EUA). É autor, entre outras obras, de O Mundo fora de Prumo: transformação social e teoria política em Shakespeare (Almedina, 2011); O Instante do Encontro: questões fundamentais para o ensino jurídico (FGV, 2012) e Narciso em sala de aula: novas formas de subjetividade e seus desafios para o ensino (FGV, 2016).

RESUMO http://lattes.cnpq.br/2258433269720331. jose.ghirardi@fgv.br

Os cursos de Direito no Brasil são organizados pelo Ministério da Educação que autorizam sua criação. Na Bahia, 14 Instituições de Ensino Superior são autorizadas a ofertar vagas semestrais ou anuais em cursos jurídicos. As Diretrizes Curriculares Nacionais (DCNs) os regulamentam, os definem como Bacharelados, apresentam as diretrizes basilares e permitem a presença de aspectos que flexibilizam o currículo do curso. As DCNs apresentam a prática jurídica como elemento de formação obrigatório, porém a definem de modo restrito, pois consideram como prática apenas atividades relacionadas às profissões jurídicas técnicas, não apresentando a docência como carreira que pode ser eleita pelo egresso do curso e que, portanto, pode ter suas atividades apresentadas no âmbito da prática jurídica. A inexistência de cursos de Licenciatura em Direito no país reforça ainda mais a necessidade de criação e introdução de instrumentos de formação didático-pedagógicos nos cursos de Graduação em Direito. O presente trabalho objetivou investigar a existência de estímulo no âmbito nestes cursos em relação à carreira docente como carreira profissional. Para tanto, com base no método indutivo, foi realizada uma revisão bibliográfica sobre o tema, tendo sido analisados os Projetos Pedagógicos destes cursos e, ainda, os editais de concursos para ingresso no magistério superior em seu corpo docente. Por fim, sustenta-se que, em razão da flexibilidade curricular, o estabelecimento de componentes obrigatórios de preparação didático-pedagógica pelos cursos é vital para incrementar a qualidade do ensino jurídico de modo a permitir uma adequada formação às futuras gerações dos bacharéis em Direito. Palavras-chave: Ensino jurídico. Direito. Docência. Desvalorização docente. Formação docente. Profissionalização da docência.

\section{LEGAL EDUCATION AT BAHIA: THE (DIS)VALUATION OF TEACHING AS A PROFESSIONAL CAREER}

\section{ABSTRACT}

Law Courses in Brazil are organized by the Ministry of Education that authorize their implementation. In Bahia, fourteen higher education institutions are authorized to offer semiannual or annual vacancies in legal courses. The National Curriculum Guidelines (NCG) regulate them, define them as bachelor degree courses, present the basic guidelines and allow the presence of aspects that make curricula more flexible. The NCG presents legal practice as an element of compulsory education, but defines it in a restricted way, as it considers practice only activities related to the technical legal professions, without presenting teaching as a career that can be chosen by students, nor does it allow teaching activities presented within the scope of legal practice. The lack of bachelor degree courses in Law in the country further stresses the need to create and implement didactic-pedagogical training tools in law degree courses. The present work aimed to investigate the existence of stimuli within these courses in relation to teaching as a professional career. To this end, based on inductive methodology, a literature review was conducted on the subject, and the Pedagogical Projects of these courses were analyzed, as well as the public tender notices for admission to higher teaching in these institutions. The paper argues that, due to the curricular flexibility, the implementation of compulsory components of didactic-pedagogical preparation by the courses is vital to increase the quality of legal education in order to allow an adequate formation for future generations of law students.

Keywords: Legal education. Law. Teaching. Devaluation teaching. Teacher training. Teaching professionalization.

\section{SUMÁRIO}

1 Introdução. 2 Os Cursos de Bacharelado em Direito no Brasil. 3 Os Cursos Públicos Jurídicos da Bahia. 3.1 Aspectos Gerais dos Cursos. 3.2 A Formação Docente nos Projetos Pedagógicos dos Cursos de Graduação. 3.3 Ingresso no Magistério Superior. 4 Os Mecanismos de Fomento à Profissão Docente. 5 Considerações Finais. 6 Referências. 


\section{INTRODUÇÃO}

Os cursos de Direito no Brasil são regulados pelo Ministério da Educação, por meio das Diretrizes Curriculares Nacionais (DCNs), que preveem que as Instituições de Ensino Superior (IES) deverão ser organizadas por intermédio dos Projetos Pedagógicos dos Cursos (PPCs). ${ }^{2}$ As DCNs, atualizadas em 2018, preveem que os PPCs devem ser estruturados em três eixos de formação obrigatórios, quais sejam: formação geral, formação técnico-jurídica e formação prático-profissional, este último composto por atividades de prática nas diversas ou principais profissões jurídicas passíveis de eleição pelo egresso do curso.

Tradicionalmente, a formação dos currículos dos cursos sempre considerou, de modo prioritário, disciplinas de caráter técnico, voltado ao estudo da letra da lei, em defesa da tese positivista (FARIA, 1987). Além disso, os alunos eram direcionados à prática de profissões tradicionais ao exercício do Direito, tais como a advocacia, a magistratura e a promotoria, razão pela qual o estágio curricular era chamado de "estágio forense", por serem realizados em Fóruns (FARIA, 1987)

A metodologia utilizada nestes cursos é calcada, de forma majoritária, em aulas expositivas, com casos raros de participação dos alunos no momento de aprendizagem em sala de aula, fato que hoje deve ser repensado, visto que os alunos devem ser considerados os protagonistas do processo de aprendizagem (GHIRARDI, 2015).

Em razão desse histórico, em meados da década de 70 do século 20, foi diagnosticada uma "crise no ensino jurídico", a qual reclamou a necessária reestruturação dos cursos, com uma reformulação dos currículos, bem como mudanças na metodologia de ensino, visando à formação adequada de profissionais aptos a atuarem em todas as áreas jurídicas, de forma ética (FARIA, 1987).

Os anos iniciais do século 21 foram marcados por uma grande expansão da quantidade de cursos de ensino superior no Brasil, devido à criação do Programa de Apoio a Planos de Reestruturação e Expansão das Universidades Federais (Reuni), que ocasionou uma grande ampliação de vagas para ingresso nos cursos públicos, além da adoção de um sistema de democratização deste ingresso: as cotas raciais e sociais (BRASIL, 2012). Além disso, as vagas em Instituições de Ensino particulares também foram ampliadas, por conta da criação do Programa Universidade Para Todos (Prouni), que fornece bolsas de estudo para egressos do Ensino Médio da rede pública de ensino ou da rede particular, na condição de bolsistas integrais (BRASIL, 2012).

O ensino jurídico na Bahia também recepcionou essa expansão, com a criação de três cursos no ensino público, totalizando 14 cursos de Direito no Estado (Ufba, 2008; Ufob, 2018; Uneb, 2013b). Fato relevante é a nomenclatura atribuída a todos estes cursos, os quais são nomeados como "Bacharelado em Direito" que, em regra, não possuem mecanismos de formação para a docência dos estudantes de Direito. Isto não seria um problema caso esses estudantes não fossem formados por professores que, em sua maioria, não cursaram, sequer, uma disciplina de Didática ao longo de seu processo de formação e que, muitas vezes, não possuem nenhum treinamento didático-pedagógico, fato este primordial para um adequado processo de aprendizagem destes profissionais que possuem uma alta relevância social.

Em razão de não existirem cursos de Licenciatura em Direito, é necessária a criação e efetivação de mecanismos que estimulem e formem os estudantes de Direito para a docência, a fim de garantir a formação adequada destes profissionais e de sua geração futura.

Este artigo visa a analisar a existência de estímulo para a formação docente no âmbito dos 14 cursos de Graduação em Direito existentes nas universidades públicas do Estado da Bahia e sua postura formativa em relação à carreira docente como uma possibilidade efetiva de carreira profissional para seus egressos. 0 percurso metodológico utilizado para desenvolver essa análise inicia-se por um levantamento bibliográfico referente ao histórico do currículo e metodologia de ensino utilizados no país. Em seguida, é apresentada uma análise dos Projetos Pedagógicos destes cursos, bem como dos editais de concursos para ingresso no magis-

\footnotetext{
${ }^{2}$ A Lei no 9.394/1996, que institui as diretrizes e bases da educação no país, aponta em seu artigo 9o as competências da União na área da educação, entre as quais se encontra a criação de normas gerais para os cursos de ensino superior (inciso VII). Esta competência foi delegada administrativamente para o Ministério da Educação, o qual institui as Diretrizes Curriculares para os Cursos de Graduação e, no âmbito jurídico, para os cursos de Graduação em Direito (BRASIL, 2018). As normas estabelecidas por essas diretrizes devem ser observadas por todas as Instituições de Ensino Superior que possuem autorização para criar cursos de Graduação em Direito.
} 
tério superior nos cursos jurídicos do Estado da Bahia. Ao final, é realizada uma discussão sobre os aspectos encontrados nos documentos que dizem respeito ao fomento da profissão docente nestes cursos e, por fim, destaca-se quais elementos podem ser expandidos e quais podem ser revistos pelas suas respectivas coordenações.

\section{OS CURSOS DE BACHARELADO EM DIREITO NO BRASIL}

Com a independência política do Brasil houve a necessidade de um grande contingente de profissionais com vasto conhecimento jurídico, a fim de formar a base dos poderes políticos do país recém-criado. Para tanto, era necessária a criação de um curso de Direito no país, visto que o acesso a estes cursos era restrito às famílias de alto poder aquisitivo, que podiam enviar os seus filhos para estudar em Coimbra, destino mais procurado para este fim (SILVA, 2019).

Após diversas tentativas frustradas da elite brasileira, os primeiros cursos jurídicos no país foram criados em 1827, nas cidades de São Paulo e de Olinda. Nessa época,

os cursos jurídicos brasileiros (...) tiveram como objetivos a formação de quadros para a administração pública e para a atividade política do Império. (...) Os cursos tinham duração de cinco anos, tendo no último período a cadeira "Teoria e prática do processo adotado pelas leis do Império" (OLIVEIRA, 2004, p. 38).

A organização curricular dos cursos de Direito no Brasil calcou-se, num primeiro momento, em disciplinas de caráter geral, agrupadas nas chamadas "cadeiras". Os conteúdos relacionavam-se com o contexto da época, logo priorizava-se o estudo do Direito Público, tendo como base o Direito Imperial, forma de governo à época, do Direito Mercantil e Marítimo, relacionado ao tipo de comércio, além do Direito Criminal e do Direito Civil. Ademais, em razão do poder ideológico que a Igreja Católica exercia durante o Império, as primeiras faculdades de Direito, tinham em seu currículo disciplinas voltadas ao estudo do Direito Eclesiástico (KRÜGER, 2019).

Com a Proclamação da República, o currículo foi revisado, de modo que diversas disciplinas foram introduzidas, tais como Direito Romano e Filosofia do Direito. Desse modo, a organização curricular que, anteriormente, possuía caráter extremamente técnico, passa a admitir algum conteúdo humanístico.

Até aqui, o currículo não admitia nenhuma flexibilidade, isto é, o aluno apenas poderia estudar as disciplinas determinadas para as cadeiras do ano em que se encontrava. A começar da Resolução no 3 redigida em 1972 pelo Conselho Federal de Educação, o currículo dos cursos de Direito passou a ter regras diferentes no tocante à carga horária mínima, com a definição de componentes curriculares obrigatórios que foram mais bem demarcados, deixando de ser referidos como "cadeiras" e passando a ser organizados em disciplinas básicas e profissionais (KRÜGER, 2019).

A partir da referida Resolução, o currículo teve, pela primeira vez, flexibilidade, o que possibilitou que as Instituições de Ensino criassem e disponibilizassem outros componentes curriculares que não constavam na grade curricular obrigatória. Desse modo, possibilitava-se que as Instituições de Ensino criassem habilitações diferentes em um mesmo curso, com a oferta, por exemplo, de disciplinas de caráter didático-pedagógico a fim de habilitar profissionais jurídicos para a docência. Isto, entretanto, não ocorreu no país.

Em meados da década de 80, Eduardo Faria denuncia uma crise no ensino jurídico. 0 tradicional enfoque em disciplinas de caráter técnico durante a história do ensino jurídico no Brasil resultou em

um ensino unidisciplinar, meramente informativo, despolitizado, massificador, adestrador e dogmático, estruturado em torno de um sistema jurídico tido como autárquico, auto-suficiente, completo, lógico e formalmente coerente ou ser uma "atividade verdadeiramente cientifica" eminentemente crítica e especulativa (FARIA, 1987, p. 27).

Nesse sentido, o autor demonstra a importância da expansão de disciplinas de caráter humanístico, que induzam o aluno a refletir sobre a realidade e o importante papel do operador jurídico na sociedade, visto que este atua diretamente com os conflitos sociais e, para solucioná-los efetivamente, necessita de um aprendizado que priorize o contexto social em suas análises. 
O ensino adequado destas disciplinas é essencial para discussões produtivas e assimilação correta do conteúdo, visto que "ensinar não é transferir conhecimento, mas criar as possibilidades para a sua produção ou a sua construção" (FREIRE, 1996, p. 13) e o professor, mediante uma formação adequada, é o responsável por essa mediação entre conhecimento e aluno.

Nos cursos de Graduação em Direito, porém, o processo de construção de saberes é preocupante, pois "os atuais métodos de ensino (...) caracterizam-se pelo predomínio de técnicas que impedem o desenvolvimento de um espírito crítico por parte do aluno, procurando torná-lo objeto de uma educação 'domesticadora' e 'bancária'" (FARIA, 1987, p. 66). Entre estas técnicas, é possível citar a repetição de teorias sem articulação com o contexto social.

Além disso, observa-se que muitos professores ditam ou escrevem na lousa os assuntos a serem expostos, os quais constam, de forma similar, em livros da doutrina que, por muitas vezes, são escritos por esses mesmos professores. Também pode-se perceber a falta de interação entre professor e aluno na sala de aula, o que induz este último a apenas memorizar o que foi dito em aula, não realizando uma reflexão crítica e contextualizada sobre o assunto (GHIRARDI, 2015).

O problema da metodologia de ensino nos cursos jurídicos pode ser justificado pelo fato de não existirem, no país, cursos de Licenciatura em Direito. Desse modo, todos os professores são formados bacharéis que, na maioria das vezes, não possuem nenhuma formação didático-pedagógica, indispensável para desempenhar a docência como prática de construção do conhecimento.

Apesar disso, não é impossível que uma Instituição de Ensino Superior disponibilize, aos seus alunos, conteúdos relacionados à prática docente, visto que o próprio Ministério da Educação permite que as Instituições criem e disponibilizem componentes curriculares livres que se adéquem ao perfil dos seus alunos, com a finalidade de estarem mais aptos ao mercado de trabalho na área em que possuírem maior afinidade.

Sobre este problema, Musse e Freitas Filho (2015, p. 177) versam que "a profissão de docente em curso jurídico requer o domínio de conhecimentos didático-pedagógicos e técnicos-científicos que, articulados à ética, promoverão um processo de ensino-aprendizagem de qualidade" e, apesar disso, atestam que "a prática desses professores é eminentemente intuitiva e predominantemente solitária, baseada em suas reflexões sobre seus erros e acertos, não tem técnica" (GUIMARÃES, 2010, p. 133 apud MUSSE; FREITAS FILHO SILVA, 2015).

Os defensores da continuação da perspectiva restrita de formação docente em Direito indicam como justificativa o artigo 66 da Lei de Diretrizes e Bases da Educação, o qual informa que "a preparação para o exercício do magistério superior far-se-á em nível de pós-graduação, prioritariamente em programas de mestrado e doutorado" (BRASIL, 1996). É importante ressaltar, porém, que a escolha da Pós-Graduação a ser realizada após a conclusão do curso é baseada, de forma prioritária, nas afinidades do aluno com as áreas estudadas e vividas durante sua Graduação. Deste modo, não há como os alunos se interessarem pela carreira docente, sem a vivência ou o conhecimento sobre essa atividade profissional.

Em razão da importância da docência, torna-se indispensável estímulos ao magistério superior ainda durante a Graduação, a fim de que, no futuro, este profissional não considere a docência uma atividade profissional menor, uma segunda ocupação com a finalidade de obter maior reconhecimento social ou, ainda, maior poder aquisitivo, preterindo a preocupação com a formação da futura geração de docentes em Direito.

A importância desse tema torna relevante, assim, que haja dados empíricos sobre as práticas de formação docente nos cursos de Direito no Brasil. O presente estudo busca analisar, nos cursos públicos de Graduação em Direito do Estado da Bahia, a existência e características das metodologias utilizadas que objetivam o fomento e a vivência da carreira docente para seus graduandos e graduandas.

\section{OS CURSOS PÚBLICOS JURÍDICOS DA BAHIA}

Na Bahia, o primeiro curso jurídico foi instalado em 1891, com a criação da Faculdade Livre de Direito da Bahia. Localizada na capital do Estado, foi federalizada no ano de 1956 e hoje é denominada Faculdade de Direito da Universidade Federal da Bahia (Ufba), que conta com dois cursos distintos, quais sejam, o curso de Graduação em Direito e o curso noturno de Bacharelado Profissionalizante em Direito (UFBA, 2019). 


\section{Debate}

A capital conta, ainda, com um terceiro curso de Direito, o qual foi criado em 2004 e é administrado pela Universidade Estadual da Bahia (Uneb). Preocupada com a democratização do acesso ao Ensino Superior, esta Universidade oferece, além deste, outros sete cursos em cidades diferentes, em todas as regiões do Estado (UNEB, 2019).

Outras quatro Universidades também oferecem cursos de Direito na Bahia em cidades localizadas no interior do Estado. São elas: Universidade Estadual de Feira de Santana (Uefs), Universidade Estadual do Sudoeste da Bahia (Uesb), Universidade Estadual de Santa Cruz (Uesc) e a recém-criada Universidade Federal do Oeste da Bahia (Ufob), totalizando 14 cursos jurídicos públicos no Estado (BRASIL, 2019).

Conforme indicado nas Diretrizes Curriculares Nacionais, todos estes cursos organizam-se por meio de Projetos Pedagógicos que apresentam os componentes curriculares e atividades acadêmicas disponíveis para os alunos das respectivas Instituições de Ensino. Para analisar o perfil geral dos cursos jurídicos baianos de ensino público em relação ao fomento à carreira docente, é necessário, preliminarmente, entender o contexto de cada um deles.

\subsection{Aspectos Gerais dos Cursos}

O primeiro curso criado no Estado realizou uma reestruturação curricular no ano de 2007, a qual abrangeu também propostas de docentes e discentes da Faculdade. O Projeto de Reestruturação do Curso que deu origem ao novo Projeto Pedagógico apresenta os principais aspectos do curso, bem como as melhorias que foram instauradas no período. A proposta afirma a necessidade de reinventar os principais objetivos dos cursos universitários tradicionais, tais como a ideia de que "o professor comandava, assim, todas as ações da sala de aula" (UFBA, 2007, p. 10). De outro modo, passou-se a entender "que o professor deve operacionalizar a troca e a cooperação de saberes" (UFBA, 2007, p. 10), propondo, com isso, a teoria construtivista que tem como principal expoente Jean Piaget, a qual possui preocupações como a necessária horizontalidade na relação entre docentes e discentes (PIAGET, 1987).

Importante é também destacar que, segundo o documento em análise, o curso pretende "formar bacharéis em Direito com uma sólida formação ético-humanista e um embasamento técnico-científico para compreender, problematizar e operacionalizar os institutos do ordenamento jurídico" (UFBA, 2007, p. 13), possibilitando, assim, atuação de forma crítica, observando a realidade social.

Com base nas diretrizes do Programa de Apoio aos Planos de Reestruturação e Expansão das Universidades Federais (Reuni), a Universidade Federal da Bahia propôs, no ano de 2008, a criação de um novo curso de Direito nesta mesma instituição de ensino. $O$ intuito da proposta seria possibilitar o acesso a um curso gratuito de Direito na cidade para aqueles cidadãos que possuem outras ocupações durante o dia.

É demonstrada, no documento, a preocupação da Universidade em relação à formação de um profissional atualizado socialmente e dotado de pensamento crítico, sob o ponto de vista ético e moral. Revela-se também no tópico "Perfil do Egresso", que "o futuro egresso será capaz de situar-se criticamente diante do sistema jurídico vigente, no sentido de pensar e observar a atividade que pratica sob perspectiva tanto quanto possível externa, tentando abarcar a compreensão do todo social" (UFBA, 2008, p. 3).

O terceiro curso do ensino público de Direito localizado na capital foi criado pela Resolução no 288/2004 do Conselho Universitário da Universidade do Estado da Bahia, tendo a sua autorização publicada no Diário Oficial do Estado da Bahia em 23 de julho de 2004. O Projeto Pedagógico do Curso de Direito da Uneb Campus Salvador apresenta a finalidade do curso:

Formar bacharéis em Direito com forte concentração de estudos interdisciplinares nas áreas das ciências humanas e sociais direcionados ao exercício das diversas atividades da área jurídica, para o compromisso com o ideal de justiça e com o processo de transformação social (UNEB, 2011d, p. 103).

O texto ainda reforça que a formação será pautada no respeito à Constituição Federal de 1988, refletindo "uma formação humanista, crítica, interdisciplinar, técnico-jurídica e política comprometida com o processo de transformação da sociedade" (UNEB, 2011d, p. 103). 
A Universidade do Estado da Bahia possui campi em diversas cidades baianas espalhadas em várias regiões do Estado. Os Projetos Pedagógicos dos cursos são bastante similares, apresentando organização curricular, objetivos e características muito semelhantes, visto que a administração do curso é realizada pelo mesmo ente federado.

Dessa forma, há de se destacar que todos os cursos organizam o seu currículo em quatro Eixos de Formação: Eixo de Formação Geral, Eixo de Formação Profissional, Eixo de Formação Prática e o Eixo Interdisciplinar. Além disso, os cursos possuem a relevante preocupação da formação do profissional com base no contexto social. O Projeto Pedagógico do curso da Uneb localizado em Brumado afirma que

o bacharel em Direito formado pela Uneb, terá condições de compreender a dinâmica da prática técnico-jurídica na sociedade, procurando solucionar problemas apresentados pelas exigências sociais, uma vez que, no seu processo formativo estarão privilegiados a capacidade de análise, domínio conceitual da terminologia jurídica e de demais campos que fazem interface com o Direito, subsidiando-o na argumentação, interpretação e valorização dos fenômenos jurídicos e sociais (UNEB, 2011c, p. 125).

A segunda maior cidade do Estado também recepciona um curso gratuito de Direito, por meio da Universidade Estadual de Feira de Santana (Uefs). O Projeto Pedagógico deste curso aponta para o cumprimento das Diretrizes Curriculares Nacionais quando afirma que

vem formando profissionais nos moldes recomendados pela Resolução CNE/CES n.09/2004, no art. 4ํㅡ, ao tratar das "habilidades e competências", ou seja, dotados de capacidade de leitura, compreensão e elaboração de textos, atos e documentos jurídicos ou normativos, com a devida utilização das normas técnico-jurídicas, interpretação e aplicação do Direito, pesquisa e utilização da legislação, da jurisprudência, da doutrina e de outras fontes do Direito, percepção de atuação nas áreas administrativa e judicial, domínio da terminologia jurídica, competência para utilização da hermenêutica e da argumentação jurídica, bem como condições para tomar decisões e dominar técnicas e métodos de compreensão e aplicação do Direito (UEFS, 2017, p. 57).

Existem, ainda, duas Universidades Estaduais que ofertam o curso de Direito no Estado, são elas: a Universidade Estadual do Sudoeste da Bahia (Uesb) e a Universidade Estadual de Santa Cruz (Uesc).

A Universidade Estadual do Sudoeste da Bahia foi criada em 1980 e, hoje, possui 3 campi localizados em cidades diferentes da região sudoeste baiana: Jequié, Vitória da Conquista e Itapetinga. O curso de Bacharelado em Direito, que está instalado na cidade de Vitória da Conquista, foi autorizado em 4 de dezembro de 2003 e, segundo o seu Projeto Pedagógico, possui "uma concepção técnico-científica vinculada ao estudo da Ciência Jurídica nas diversas formas da realidade em que se revela a aplicação do Direito segundo as demandas da sociedade, em prol do equilíbrio social" (UESB, 2011, p. 40). O documento expõe a importância da relação da Universidade com a sociedade e, por isso, reforça a necessária ideia de que

o bacharel em Direito a ser formado pela UESB deverá estar consciente de que além do exercício da profissão jurídica que escolher, possui compromisso sociopolítico com o aperfeiçoamento das instituições de jurídicas e dever ético decorrente do exercício de sua função pública (UESB, 2011, p. 41).

O curso de Direito da Universidade Estadual de Santa Cruz está localizado na cidade de Ilhéus e foi aprovado pelo Conselho Superior de Ensino, Pesquisa e Extensão desta Universidade em 13 de fevereiro de 2012. Segundo o seu Projeto Pedagógico, o curso deverá

oportunizar ao graduando uma sólida formação geral e humanística, com a capacidade de análise e articulação de conceitos e argumentos, de interpretação e valorização dos fenômenos jurídicos e sociais, aliada a uma postura reflexiva e visão crítica que fomente a capacidade de trabalho em equipe, favoreça a aptidão para a aprendizagem autônoma e dinâmica, além da qualificação para a vida, o trabalho e o desenvolvimento da cidadania (UESC, 2012, p. 2).

Entre as aptidões que o estudante deve obter durante o curso, apenas foram encontradas aquelas que se relacionam com o exercício de profissões jurídicas técnicas, tais como a magistratura e a advocacia. Exemplo destas aptidões são 
Adequada atuação técnico-jurídica, em diferentes instâncias, administrativas ou judiciais, com a devida utilização de processos, atos e procedimentos; (...) julgamento e tomada de decisões; e domínio de tecnologias e métodos para permanente compreensão e aplicação do Direito (UESC, 2012, p. 3).

O último curso a ser criado no Estado foi o Bacharelado em Direito administrado pela Universidade Federal do Oeste da Bahia, instalado no segundo semestre de 2014. Segundo o seu Projeto Pedagógico, o curso possui como princípio maior o comprometimento "com o Acesso à Justiça e a confirmação dos Direitos Humanos" (UFOB, 2018, p. 6). Neste sentido, o Projeto Pedagógico do curso

foi elaborado com uma nova concepção da norma jurídica a partir da sua aplicabilidade e eficiência. Em vez de Ihe atribuir um caráter punitivo ou repressivo, prefere-se pensar essa norma como um elemento norteador da efetividade das políticas públicas e da pacificação social (UFOB, 2018, p. 6).

Além das características gerais, os Projetos Pedagógicos dos cursos também definem o perfil dos profissionais que desejam formar, apontando para as carreiras nas quais os seus estudantes estarão aptos a ingressar. Desse modo, analisar-se-á a presença de instrumentos de apresentação da profissão docente aos estudantes dos cursos jurídicos baianos do ensino público.

\subsection{A Formação Docente nos Projetos Pedagógicos dos Cursos de Graduação}

A organização dos cursos jurídicos baianos é realizada das mais diferentes formas, segundo as diferentes opções abraçadas pelas Instituições de Ensino Superior. Dentro dessa variedade de formas e opções, importa analisar a existência ou inexistência de mecanismos que fomentam a carreira docente aos estudantes desses cursos, ou mesmo o mero conhecimento da docência como passível de eleição pelo egresso dos cursos. Essa seção analisa os Projetos Pedagógicos desses cursos.

Os Projetos Pedagógicos que organizam os cursos de Direito da Universidade Estadual de Feira de Santana e da Universidade Federal da Bahia apresentam a carreira docente por meio da monitoria, como atividade complementar do curso, cujo objetivo é a prática, pelo aluno, de atividades referentes ao magistério superior, porém são deficientes no que toca ao modo de realização.

O documento elaborado pela Uefs afirma que a atividade de monitoria permite o convívio e o exercício da carreira docente por meio do auxílio aos docentes em atividades da profissão (UEFS, 2017). A participação dos estudantes nessas atividades, contudo, é limitada, na medida em que, para fins de contabilização da carga horária, apenas é permitida a realização da monitoria remunerada, a qual se limita aos recursos orçamentários da Pró-Reitoria de Graduação dessa Universidade.

O Projeto Pedagógico do curso mais antigo da Universidade Federal da Bahia busca "capacitar o aluno para atuar nas diversas áreas jurídicas, inclusive no magistério superior, seja perante os órgãos públicos ou na área privada" (UFBA, 2007, p. 16). Além disso, as atividades complementares do curso abrangem, segundo a proposta, "a pesquisa, a extensão, a monitoria e a freqüência a disciplinas extracurriculares e a defesa de teses e dissertações de mestrado" (UFBA, 2007, p. 33).

Entre essas atividades pode-se sinalizar a monitoria como um espaço que poderá possibilitar a prática docente durante o curso, pois, segundo a proposta, "a monitoria será exercitada inclusive com fins pedagógicos, profissionalizante, bem como desenvolver aptidões do aluno em diversas áreas específicas e em projetos" (UFBA, 2007, p. 3). O documento define esta atividade como aquela realizada "junto a professores de disciplinas que integrem a grade curricular do Curso de Direito e têm como objetivo desenvolver as habilidades do aluno para o magistério superior" (UFBA, 2007, p. 34).

O Curso Noturno de Bacharelado Profissionalizante em Direito, administrado pela mesma Universidade, assim como o curso regular, não apresenta a preparação para a docência como prática jurídica, mas sim como Atividade Complementar, por meio das atividades de monitoria, que "compreendem o exercício de atividade junto a professores de disciplinas que integrem a grade curricular do Curso de Direito e têm como objetivo desenvolver as habilidades do aluno para o magistério superior" (UFBA, 2008, p. 10). 
Outras Instituições de Ensino detalham mais a fundo, em seus documentos, a atividade de monitoria, demonstrando de que forma essas atividades serão realizadas, a fim de disponibilizar uma adequada e efetiva prática docente aos estudantes de Graduação. Essa foi a opção dos cursos de Direito administrados pela Universidade Federal do Oeste da Bahia e da Universidade do Estado da Bahia, em seu Campus I, localizado na cidade de Salvador.

O curso de Direito da Universidade do Estado da Bahia, localizado na capital do Estado, apresenta, em seu Projeto Pedagógico, a relação entre teoria e prática incluindo a prática docente, informando que

o curso está orientado para articular teoria e prática em todos os Componentes Curriculares, desde o primeiro semestre, porque compreende a prática docente como práxis, o que se materializa mediante uma prática de ensino que trate pedagogicamente a análise de documentos e situações-problema, estudos de caso, jurisprudência, visitas planejadas, júri simulado, peças processuais, tomando por base os estudos teóricos realizados no âmbito dos Componentes Curriculares. Além dessa prática pedagógica operada nos cinco anos do curso, o espaço do Estágio e Prática Jurídica, a partir do oitavo semestre, garantirá a interface dos diferentes temas no exercício prático intra e extra sala de aula. A prática de ensino terá conteúdos próprios, com destaque especial para os procedimentos de observação e reflexão para compreender as situações contextualizadas, tais como registro de observações realizadas e a resolução de situações-problema características do cotidiano profissional (UNEB, 2011d, p. 107).

O documento apresenta ainda as atividades complementares, que são previstas no currículo com a finalidade de flexibilizá-lo, e abrangem atividades como a de monitoria, que podem ser desenvolvidas desde o primeiro semestre do curso.

Em relação ao curso de Direito da Universidade Federal do Oeste da Bahia, este apresenta o fomento à prática docente em diversos aspectos do Projeto Pedagógico dos Cursos. Inicialmente, o documento não cita Instituições de Ensino como locais para o exercício da profissão jurídica, fato este que pareceria excluir a docência do rol de profissões jurídicas que o bacharel em Direito poderá seguir.

No tocante às atividades complementares, entretanto, suas diretrizes demonstram o "fortalecimento da articulação entre teoria e prática, valorizando o desenvolvimento de potencialidades individuais e coletivas para o ensino, a pesquisa e a extensão" (UFOB, 2018, p.54). A fim de ofertar uma atividade para a prática do ensino, o documento apresenta a monitoria como um

programa formativo que incentiva e amplia os espaços de aprendizagem do estudante de graduação, compartilhando com o professor vivências relacionadas às atividades de ensino, mediante participação em projetos acadêmicos, sob a orientação de um professor, no âmbito desta universidade (UFOB, 2018, p. 94).

Entre os objetivos desse programa formativo está o "despertar o interesse pela docência mediante o envolvimento do estudante do Projeto de Monitoria de Ensino em práticas e experiências didático-pedagógicas" (UFOB, 2018, p. 94). Dessa forma, pode-se definir a monitoria como um dos espaços essenciais para a formação do docente em Direito, pois permite a vivência nos espaços de criação de aulas, bem como de aplicação destas, possibilitando uma capacitação didático-pedagógica essencial a qualquer docente.

A Universidade Estadual do Sudoeste da Bahia optou por apenas mencionar a carreira docente no Projeto Pedagógico que organiza o seu curso de Direito. Essa Instituição de Ensino também cita a existência da monitoria, mas não a aponta como possível espaço de prática jurídica. Assim, é possível afirmar que nenhuma das disciplinas previstas no Projeto Pedagógico dessa instituição prevê explicitamente a formação dos alunos para a carreira docente. De outro modo, a prática apresentada no documento cita apenas profissões jurídicas ditas tradicionais e, mais especificamente, a advocacia.

No tocante às atividades complementares, o curso divide-se nos eixos ensino, pesquisa e extensão. No eixo ensino são previstas as atividades: "Seminários Temáticos, Disciplinas Extracurriculares, Cursos de Línguas, Cursos de Informática, Monitorias" (UESB, 2011, p. 80), em que apenas a monitoria pode ser utilizada como instrumento de formação docente; não existem detalhes, porém, sobre a forma pela qual esta atividade é realizada e fomentada na Universidade, como também não existe referência, no Projeto Pedagógico do curso, sobre a monitoria ser um espaço de prática docente. 
Outro mecanismo utilizado para possibilitar a prática docente, ainda na Graduação em Direito, é a utilização do Programa Institucional de Bolsas de Iniciação à Docência, administrado pelo governo federal e, geralmente, aplicado aos cursos de Licenciatura. De forma singular, porém, a Universidade Estadual de Santa Cruz apresenta-o como espaço de prática docente em um curso de Bacharelado.

Nesse sentido, o Projeto Pedagógico deste curso não traz, entre as disciplinas obrigatórias previstas em seu currículo, componentes que se relacionem à prática docente durante o curso, que mantém a tradição de somente considerar como prática o estágio supervisionado. No eixo referente às atividades complementares que podem ser realizadas pelos alunos, porém, ressalta-se a "Participação em Projeto de Iniciação à Docência" (UESC, 2012, p. 6), referência ao Programa Institucional de Bolsas de Iniciação à Docência (Pibid). Esta possibilidade expande o olhar dos estudantes, apresentando a oportunidade de uma efetiva capacitação didático-pedagógica para a possível escolha da carreira docente após a finalização do curso.

Os demais sete cursos analisados apresentam posicionamentos semelhantes entre si: eles não tratam a docência como prática jurídica, nem fomentam atividades de iniciação à docência, apenas apresentando atividades extracurriculares, cuja escolha fica a cargo dos alunos, podendo ou não serem relacionadas ao exercício da profissão docente, as quais não são apresentadas como oportunidade clara pelo Projeto Pedagógico.

Pode-se observar essa escolha nos Projetos Pedagógicos dos cursos de Direito da Universidade do Estado da Bahia, localizados nas cidades de Brumado, Camaçari, Itaberaba, Jacobina, Juazeiro, Paulo Afonso e Valença. Esses cursos silenciam a apresentação da docência aos seus alunos como carreira, visto que não apresentam explicitamente nenhuma atividade ou componentes curriculares que possibilitem a experiência docente durante o curso.

Para além das previsões dos Projetos Pedagógicos, o estímulo da prática docente pode ser investigado também ao se examinar os editais de concurso para ingresso na carreira docente nestes cursos, visto que critérios relacionados à existência ou inexistência de capacitação didático-pedagógica, bem como de efetiva prática docente dos candidatos, pode indicar o perfil de profissional que a Instituição de Ensino deseja no seu quadro funcional.

\subsection{Ingresso no Magistério Superior}

Para o ingresso em carreira pública, nossa Constituição Federal decreta a obrigação da utilização do concurso público de provas e títulos, conforme prevê o artigo 32, inciso II da Carta Magna:

II - a investidura em cargo ou emprego público depende de aprovação prévia em concurso público de provas ou de provas e títulos, de acordo com a natureza e a complexidade do cargo ou emprego, na forma prevista em lei, ressalvadas as nomeações para cargo em comissão declarado em lei de livre nomeação e exoneração.

Por essa razão e em decorrência do princípio da publicidade, os cursos de Direito baianos da educação pública mantêm disponíveis, para acesso do público em geral, os documentos referentes aos últimos concursos públicos realizados com a finalidade de selecionar novos docentes para as respectivas Instituições de Ensino Superior e, mais especificamente, para os cursos de Direito dessas Instituições.

Todos os referidos cursos exigem, como requisito mínimo para concorrência às vagas para ingresso efetivo no magistério superior, diploma de Graduação em Direito e, também, Mestrado em Direito ou em áreas afins. No tocante às contratações de caráter temporário, suas seleções exigem um menor nível de formação, mantendo o requisito de Graduação em Direito, porém exigindo apenas Especialização em Direito ou em áreas afins (UEFS, 2011; UESB, 2013; UESC, 2013; UFBA, 2014; UFOB, 2017; UNEB, 2013a).

Outro fator comum encontrado entre os editais de concurso é o modo pelo qual acontece a seleção dos professores. Usualmente ocorre a entrega de documentos e, após isso, uma prova escrita, uma prova didática e, por fim, uma prova de títulos. Os documentos ainda mencionam o modo de cálculo da média final entre as notas atribuídas a cada prova, bem como os critérios de desempate, de forma ordenada.

A prova escrita consiste em uma dissertação na qual o candidato deverá expor, de maneira organizada, toda a sua base sobre o tema em análise. Além de objetivar a exposição do conhecimento do candidato acerca da área, os editais de concurso analisados revelam que as finalidades dessa etapa são para avaliar o conhecimento do candidato sobre a matéria e a sua capacidade de expressão em linguagem técnica. 
A prova didática consiste "de uma aula de natureza discursiva no campo da argumentação teórica" (UEFS, 2011, p. 4) e objetiva "aferir a erudição, clareza na exposição, proficiência e atualidade dos conhecimentos do candidato no que tange à área/subárea de conhecimento do concurso" (UFBA, 2014, p. 5). Segundo o edital de concurso realizado pela Universidade Estadual de Santa Cruz, realizado no ano de 2013, o objetivo desta fase do processo seletivo seria avaliar o desempenho didático-pedagógico do candidato (UESC, 2013, p. 5).

A prova de títulos consiste na entrega do currículo do candidato, com as devidas certificações, para fins de identificação de atividades acadêmicas e profissionais realizadas em área relacionada à área do concurso. Cada atividade apresentada pode ser pontuada igualmente, como é o caso do concurso realizado pela Universidade Estadual de Feira de Santana, ou de forma distinta, com pontuação atribuída de forma diferenciada a cada espécie de atividade que o candidato realizou, a exemplo do concurso realizado pela Universidade do Estado da Bahia.

Algumas Instituições de Ensino Superior adotam outro tipo de dinâmica, com a introdução de outros critérios de seleção, além dos já apresentados. Nesse sentido, os concursos realizados pela Universidade Federal da Bahia abrangem também a chamada defesa de Memorial, que se refere a uma exposição discursiva que conterá a descrição e

a análise da produção científica, artística e cultural, das atividades didáticas, de extensão, de formação, administrativas e de orientação na área/subárea do concurso ou em áreas/subáreas correlatas; a descrição de outras atividades relacionadas às áreas/subáreas de conhecimento em exame; e as perspectivas de trabalho, projetos acadêmicos e possíveis contribuições para o desenvolvimento institucional (UFBA, 2014, p. 5).

Em referência à Universidade Federal do Oeste da Bahia, esta utiliza, na primeira fase do concurso, além da prova escrita e da prova oral, uma Defesa da Proposta de Atuação Acadêmica, a qual "visa avaliar o candidato quanto à sua capacidade de articulação das atividades de ensino, pesquisa e extensão, fundamentada em sua trajetória de formação acadêmica" (UFOB, 2017, p. 10).

A cada fase do processo avaliativo a comissão avaliadora atribuirá nota entre 0 e 10. Em geral, será considerado classificado o candidato que obtiver média aritmética maior que 7 e selecionado aquele com maior média aritmética. Algumas Instituições de Ensino, porém, preferem realizar o cálculo de maneira distinta, atribuindo "pesos" a cada prova. Dessa maneira, a Universidade Estadual de Santa Cruz, a Universidade Federal da Bahia e a Universidade Federal do Oeste da Bahia atribuem valores de pesos similares às provas escrita e oral.

Os editais também apresentam critérios de desempate, os quais visam a evitar que dois ou mais candidatos sejam considerados selecionados para uma mesma vaga. Nesse sentido, a maioria dos editais de concurso estabelece que o candidato de maior nota na prova didática tenha prioridade na ordem de critérios de desempate em relação às demais provas. A exceção desta regra encontra-se nos editais de concurso realizados pela Universidade Estadual de Santa Cruz, a qual prioriza o candidato que alcançou maior nota na prova escrita. É importante salientar, no entanto, que essa é a única das instituições analisadas que, entre os critérios de desempate da seleção, apresenta o critério de tempo de serviço no magistério superior.

A partir tanto dos elementos encontrados nos Projetos Pedagógicos e Editais de Concurso apresentados nesta seção, é possível analisar o grau de fomento à carreira docente por meio da existência ou não de atividades relativas à profissão, no currículo do curso, ou ainda da necessidade ou não de capacitação didático-pedagógica para o ingresso na carreira.

\section{OS MECANISMOS DE FOMENTO À PROFISSÃO DOCENTE}

O despertar para a profissão docente inicia-se na Graduação, pois o estudante mantém contato com as mais diversas áreas do Direito, traçando, assim, suas afinidades. Nos últimos semestres do curso o aluno deve tomar a decisão crucial de que carreira seguir e em qual área se especializar.

Sinteticamente, são ofertadas duas carreiras aos estudantes de Direito: a carreira acadêmica e a carreira técnica. Caso o egresso decida-se pela carreira acadêmica, deverá se submeter a seleções de cursos de Pós-Graduação stricto sensu, a fim de ingressar em cursos de Mestrado e Doutorado, no intuito de desenvolver suas habilidades na área de pesquisa e elaboração de trabalhos técnico-científicos. 
Se a decisão for no sentido da área técnica do Direito, o egresso buscará se especializar em área específica, por meio de cursos de Pós-Graduação lato sensu, a fim de realizar especializações, que são cursos de curta duração. Com a aprovação no Exame da Ordem dos Advogados do Brasil poderá iniciar sua atuação na advocacia privada. No caso de carreira pública, deverá se preparar para realizar concursos públicos a fim de participar das próximas seleções.

Apesar, no entanto, de muito importante para o desenvolvimento da pesquisa, ensino e extensão nas universidades, a docência, muitas vezes, não é apresentada explicitamente como carreira jurídica passível de eleição pelo egresso do curso. Como foi possível perceber, nenhum curso jurídico baiano de ensino público apresenta, em seus Projetos Pedagógicos, mecanismos de prática docente como elemento de destaque em seu processo formativo. De fato, os documentos institucionais apresentam as atividades relacionadas à carreira apenas como uma atividade complementar, a qual pode ou não ser escolhida pelos estudantes do curso e que possuem uma realização muitas vezes limitada, visto que dependem da oferta pela Instituição de Ensino, de professores aptos e disponíveis para o auxílio, bem como de recursos financeiros para a realização de determinadas atividades.

O estímulo à profissão docente, iniciado na Graduação, é um fato importante, visto que é nela que o estudante define a área ou áreas do Direito com as quais possui mais afinidade e que decidirá se especializar. Este fenômeno aplica-se tanto aos estudantes que decidirem seguir uma carreira acadêmica quanto àqueles que elegerem uma carreira técnica.

Em razão da autonomia que possuem os cursos de Direito do país, as respectivas Instituições de Ensino podem criar e ofertar mecanismos que possibilitem a apresentação e a realização de atividades da prática docente, ainda durante a Graduação.

Entre os cursos analisados, cinco apresentam a monitoria como método de formação docente no decorrer da Graduação. O Regulamento de Monitorias de Ensino da Uneb apresenta esse instrumento como

uma das funções acadêmicas que, no seu papel de atividade complementar nos cursos de graduação, conforme a definem as Diretrizes Curriculares Nacionais do Conselho Nacional de Educação (CNE), além de promover maior interação entre o corpo docente e o discente, deve proporcionar oportunidades para a integração da teoria com a prática na formação do futuro profissional (UNEB, 2009, p. 2).

Em razão de ser caracterizada como atividade não obrigatória, pode-se sugerir que seria importante inserir a formação docente, nos Projetos Pedagógicos dos cursos, como prática jurídica e não como atividade complementar. Viabilizar o contato entre o estudante do curso e as atividades profissionais é primordial para a correta escolha e preparação para a vida profissional e este fato aplica-se também à profissão docente.

O Programa Institucional de Bolsas de Iniciação à Docência é designado como possibilidade de prática docente por apenas um dos cursos analisados. O Programa é definido pela Portaria no 096 da Coordenação de Aperfeiçoamento de Pessoal de Nível Superior (Capes), segundo o qual

é um programa da Coordenação de Aperfeiçoamento de Pessoal de Nível Superior (Capes) que tem por finalidade fomentar a iniciação à docência, contribuindo para o aperfeiçoamento da formação de docentes em nível superior e para a melhoria da qualidade da educação básica pública brasileira (CAPES, 2013, p. 2).

A Portaria institui o Regulamento do Programa, o qual versa sobre a possibilidade de estudantes de cursos de Graduação realizarem atividades de prática da profissão docente em escolas da Educação Básica de ensino público. Desse modo, o artigo 3ㅇ do Regulamento do Pibid versa que: "os projetos apoiados no âmbito do Pibid são propostos por Instituições de Ensino Superior (IES) e desenvolvidos por grupos de licenciandos sob supervisão de professores de educação básica e orientação de professores das IES" (CAPES, 2013, p. 2).

Desse modo, é possível entender que, apesar de o Projeto Pedagógico da Uesc apresentar o Programa de Iniciação à Docência como possibilidade de prática docente para o curso de Direito, não seria possível a sua realização em razão do seu Regulamento não abranger os cursos de Bacharelado, como é o caso dos cursos jurídicos do país. 
Tendo em vista os aspectos mencionados, apesar de grande parte dos cursos em análise sinalizarem expressamente sua preocupação na formação de profissionais para o exercício do magistério superior, eles não apresentam de maneira clara o modo pelo qual esta preparação será realizada, trazendo somente a monitoria como uma atividade que viabiliza uma possível formação didático-pedagógica dos seus estudantes, mas não como uma prática jurídica.

No tocante aos editais de concurso desses cursos, compreende-se que a possibilidade de profissionais docentes possuírem estudos aprofundados em áreas ditas "afins" do Direito é um dado importante para a formação dos alunos, uma vez que oportuniza a interdisciplinaridade do curso, possibilitando uma construção de conhecimentos articulados com outras áreas.

Ao recordar a Teoria Pura do Direito de Kelsen (1998), seu entendimento que prevaleceu nas Faculdades de Direito por muitas décadas, a qual compreendia o Direito de forma isolada, sem interferência de outras áreas de estudo, o que ocasionou produção de conhecimento desarticulada com o contexto social e um atraso no seu desenvolvimento como ciência em relação às demais ciências humanas (NOBRE, 2019).

Ao observar um edital de carreira na qual pretende ingressar, um aluno perceberá a exigência de requisitos relacionados à capacitação didático-pedagógico, bem como à efetiva experiência na carreira. Este fato estimula o aluno a pesquisar instrumentos de prática docente, ainda na Graduação.

Em relação aos critérios de desempate, a prioridade de seleção de candidatos que possuíram as maiores notas na prova didática caracteriza uma preocupação das Instituições de Ensino em selecionar profissionais com capacitação para o ensino. Além disso, a existência do critério de experiência na profissão em concurso recente revela o despertar da preocupação em preferir um profissional com a adequada aptidão didático-pedagógica indispensável ao futuro professor.

A Lei de Diretrizes e Bases da Educação indica que o professor de Ensino Superior deve ser preparado e capacitado na Pós-Graduação, porém seria desejável que o incentivo e estímulo a essa carreira não fossem limitados a este espaço, em razão da necessária formação de profissionais aptos a exercerem a carreira com a devida capacitação didático-pedagógica.

Os aspectos mencionados dão força à ideia de que incentivar a profissão docente desde a Graduação é um movimento importante que pode e deve ser reforçado pelos órgãos superiores da educação superior, a fim de evitar que docentes despreparados assumam vagas em espaços de formação desses profissionais de papel social tão relevante.

\section{CONSIDERAÇÕES FINAIS}

O presente artigo discutiu a ausência dos espaços específicos para a formação docente na Graduação dos cursos de Direito da educação pública na Bahia. Essa investigação insere-se no debate mais amplo sobre profissionalização docente na área jurídica, tema que vem ganhando relevância no debate acadêmico brasileiro (MUSSE; FREITAS FILHO, 2015).

Observa-se que o adensamento dos debates e a consolidação do reconhecimento da necessidade de se capacitar pedagogicamente os futuros docentes não têm se traduzido na institucionalização de loci de formação docente. Há um hiato, assim, entre a valorização docente sustentada pela crescente literatura na área e a marcada escassez de políticas institucionais destinadas à capacitação de novos quadros.

A análise realizada sobre os cursos jurídicos da educação pública na Bahia dá credibilidade a esse diagnóstico. Ela demonstrou que a grande maioria dos cursos analisados não possui componentes curriculares, nem atividades complementares que se refiram à prática docente durante a Graduação. Apesar de citarem a carreira em seus documentos institucionais, não apresentam detalhadamente a forma pela qual se dará a instituição e a realização da prática docente. Com exceção da Universidade Federal do Oeste da Bahia, que apresenta um programa com atividades bem delineadas, as demais Instituições de Ensino não explicitam suas estratégias.

No tocante aos concursos de seleções de professores, percebe-se que a didática é valorizada de forma dupla, isto é, no cálculo da média final e também nos critérios de desempate, porém é importante pensar onde este candidato realizará essa necessária capacitação, visto que não existem ou não são corretamente estabelecidos os instrumentos que possibilitam esta qualificação. 
Desse modo, surge o questionamento sobre os espaços de formação os professores dos cursos de Direito no Brasil, visto que os estudantes de Graduação não são formados nem estimulados para este fim. A pergunta é relevante, pois estudantes que são formados sem nenhuma disciplina ou atividade relacionada ao ensino serão eventualmente docentes, fato que pode comprometer a qualidade do ensino-aprendizagem das futuras gerações dos profissionais do Direito.

Apesar da referência à Pós-Graduação, sabe-se que este espaço tem objetivado, especificamente, formar pesquisadores na área, profissão cujas competências se distinguem explicitamente das competências de um profissional docente. Deste modo, na prática, não está claro o espaço que um estudante de Graduação ou Pós-Graduação em Direito deverá procurar para realizar uma formação para a docência, com as competências básicas que ela exige.

A tomada de consciência das Instituições de Ensino é o primeiro passo para a mudança dessa conjuntura. Criar mecanismos obrigatórios de preparação para a profissão docente é essencial para a formação adequada das futuras gerações de bacharéis em Direito.

\section{REFERÊNCIAS}

BRASIL. Análise sobre a expansão das universidades federais 2003 a 2012. Brasília: Ministério da Educação, 2012.

BRASIL. Cadastro Nacional de Cursos e Instituições de Educação Superior. Disponível em: http://emec.mec.gov.br/. Acesso em: 15 jul. 2019.

BRASIL. Lei no 9.394, de 20 de dezembro de 1996. Estabelece as diretrizes e bases da educação nacional. Diário Oficial [da] República Federativa do Brasil, Poder Executivo, Brasília, DF, 23 dez. 1996.

BRASIL. Resolução no: 635/2018, de 4 de outubro de 2018. Institui as Diretrizes Curriculares Nacionais do Curso de Graduação em Direito e dá outras providências. Diário Oficial [da] República Federativa do Brasil, Brasília, DF, 17 dez. 2018. Seção 1. p. 34.

CAPES. Coordenação de Aperfeiçoamento de Pessoal de Nível Superior. Portaria no 096, de 18 de julho de 2013. Disponível em: https://www.capes.gov.br/images/stories/download/legislacao/Portaria_096_18jul13_AprovaRegulamentoPIBID.pdf. Acesso em: 31 maio 2019.

FARIA, J. E. A reforma do Ensino Jurídico. Porto Alegre: Fabris, 1987.

FREIRE, P. Pedagogia da autonomia: saberes necessários à prática educativa. São Paulo: Paz e Terra, 1996.

GHIRARDI, J. G. Ainda precisamos da sala de aula? Inovação tecnológica, metodologias de ensino e desenho institucional nas faculdades de Direito. 1. ed. São Paulo: FGV Direito SP, 2015.

KELSEN, H. Teoria Pura do Direito. São Paulo: Martins Fontes, 1998.

KRÜGER, F. M. Evolução e adequação curricular do curso jurídico. Disponível em: http://www.ambito-juridico.com.br/site/index.php?n_link=revista_artigos_leitura\&artigo_id=7196. Acesso em: 31 maio 2019.

MUSSE, L. B.; FREITAS FILHO, R. Docência em Direito no Brasil: uma carreira profissional? Revista Jurídica da Presidência, Brasília, v. 17, n. 111, fev./maio 2015, p. 173-203.

NOBRE, M. Apontamentos sobre a pesquisa em Direito no Brasil. Disponível em: https://bibliotecadigital.fgv.br/dspace/bitstream/handle/10438/2779/Pesquisa_Direito_Cadernos_Direito_GV.pdf?sequence=1\&isAllowed=y. Acesso em: 31 maio 2019.

OLIVEIRA, A. M. Ensino jurídico: diálogo entre teoria e prática. Porto Alegre: Fabris, 2004.

PIAGET, J. O nascimento da inteligência na criança. 4. ed. Rio de Janeiro: Guanabara, 1987.

SILVA, E. M. T. Ensino de Direito no Brasil: perspectivas históricas gerais. Disponível em: http://www.scielo.br/scielo.php?scrip$\mathrm{t}=$ sci_arttext\&pid=S1413-85572000000100008. Acesso em: 31 maio 2019.

UEFS. Universidade Estadual de Feira de Santana. Concurso Público para Ingresso na Carreira de Magistério Superior na classe de professor auxiliar, assistente e adjunto. Feira de Santana: Uefs, 2011.

UEFS. Universidade Estadual de Feira de Santana. Projeto de Renovação de Reconhecimento do Curso de Bacharelado em Direito da Universidade Estadual de Feira de Santana. Feira de Santana: Uefs, 2017.

UESB. A Universidade Estadual do Sudoeste da Bahia. Concurso Público de Provas e Títulos para provimento de cargos de professor do magistério superior. Vitória da Conquista: Uesb, 2013.

UESB. A Universidade Estadual do Sudoeste da Bahia. Renovação de Reconhecimento do Curso de Graduação em Direito. Vitória da Conquista: Uesb, 2011.

UESC. Universidade Estadual de Santa Cruz. Concurso Público para Provimento de Cargos de Professor Auxiliar, Assistente e Adjunto, Nível "A". Ilhéus: Uesc, 2013. 
UESC. Universidade Estadual de Santa Cruz. Projeto Acadêmico Curricular do Curso de Bacharelado em Direito. Ilhéus: Uesc, 2012.

UFBA. Universidade Federal da Bahia. Edital do Concurso Público para o cargo isolado de Professor Titular-Livre do Magistério Superior. Salvador: Ufba, 2014.

UFBA. Universidade Federal da Bahia. Fundação da Faculdade de Direito. Disponível em: https://direito.ufba.br/institucional. Acesso em: 15 jul. 2019.

UFBA. Universidade Federal da Bahia. Proposta de criação do Curso Noturno de Bacharelado Profissionalizante em Direito. Salvador: Ufba, 2008.

UFBA. Universidade Federal da Bahia. Proposta de reestruturação curricular do Curso de Graduação em Direito. Salvador: Ufba, 2007.

UFOB. Universidade Federal do Oeste da Bahia. Edital do Concurso Público para Docente do Magistério Superior. Vitória da Conquista: Ufob, 2017.

UFOB. Universidade Federal do Oeste da Bahia. Projeto Pedagógico do Curso de Bacharelado em Direito. Barreiras: Ufob, 2018.

UNEB. Universidade do Estado da Bahia. Cursos Presenciais. Disponível em: https://portal.uneb.br/prograd/cursos-presenciais/. Acesso em: 15 jul. 2019.

UNEB. Universidade do Estado da Bahia. Edital no 046/2013. Salvador: Uneb, 2013a.

UNEB. Universidade do Estado da Bahia. Projeto de Reconhecimento do Curso de Bacharelado em Direito. Camaçari: Uneb, 2011 a.

UNEB. Universidade do Estado da Bahia. Projeto de Reconhecimento do Curso de Bacharelado em Direito. Jacobina: Uneb, 2010a.

UNEB. Universidade do Estado da Bahia. Projeto de Reconhecimento do Curso de Bacharelado em Direito. Paulo Afonso: Uneb, 2010b.

UNEB. Universidade do Estado da Bahia. Projeto de Reconhecimento do Curso de Bacharelado em Direito. Valença: Uneb, 2011b.

UNEB. Universidade do Estado da Bahia. Projeto do Curso de Bacharelado em Direito. Itaberaba: Uneb, $2013 \mathrm{~b}$.

UNEB. Universidade do Estado da Bahia. Projeto do Curso de Graduação em Direito - Bacharelado (Cooperação interdepartamental com o DCHT - XIX). Brumado: Uneb, 2011c.

UNEB. Universidade do Estado da Bahia. Projeto Político Pedagógico - Curso de Direito - Departamento de Ciências Humanas - Campus I. Salvador: Uneb, 2011d.

UNEB. Universidade do Estado da Bahia. Resolução no 700/2009, que aprova o Regulamento de Monitorias de Ensino da Uneb. Salvador: Uneb, 2009. 